Proceedings

\title{
Educating about Art by Augmented Reality: New Didactic Mediation Perspectives at School and in Museums ${ }^{\dagger}$
}

\author{
Chiara Panciroli *, Anita Macauda and Veronica Russo \\ Department Education Studies “G. M. Bertin”, University of Bologna, 40126 Bologna, Italy; \\ anita.macauda@unibo.it (A.M.); veronica.russo6@unibo.it (V.R.) \\ * Correspondence: chiara.panciroli@unibo.it \\ + Presented at the International and Interdisciplinary Conference IMMAGINI? Image and Imagination \\ between Representation, Communication, Education and Psychology, Brixen, Italy, 27-28 November 2017.
}

Published: 7 March 2018

\begin{abstract}
Different national and international researches have stressed relevant aspects concerning the application of augmented reality in formal and non-formal educational contexts, especially at school and in museums. In fact, augmented reality plays a meaningful role in the relationship between technologies and didactic mediation; its applications are the prerequisite for an augmented learning, through the reproduction of specific scenarios which go beyond the pure theoretical dimension. More specifically the present contribution aims to set out an option for a reflection on the relationship between art education and augmented reality technologies from the didactic mediation point of view, with reference to a shared and collaborative construction of knowledge of artistic and cultural heritage.
\end{abstract}

Keywords: augmented reality; arts; education; mediation; experience; technology; museum

\section{Introduction}

The latest developments of augmented reality technologies uncover unexpected scenarios related to learning in formal and non-formal educational contexts, in particular in schools and museums. In fact, augmented reality applicability and application to didactic fields set out as an innovative research field, whose growing experimentations provide relevant elements for a pedagogical reflection. The efficacy of the educational paths carried out through augmented reality represents one of the most interesting issues in the present debate, especially as far as the design, implementation and assessment of an augmented didactics is concerned; such augmented didactics has to be taken into consideration within a proper theoretical-methodological framework [1-6].

To such regard the 2011 Horizon Report identifies and describes emerging technologies with relevant impact on the fields of teaching, learning, research and creative expression. Among such technologies augmented reality can be found; it can be used for visual and highly interactive types of learning, which enrich the real world with the overlapping of digital data and the simulation of dynamic processes. "This interactivity confers significant potential for learning and assessment. Augmented reality is an active, not a passive technology; students can use it to construct new understanding based on interactions with virtual objects that bring underlying data to life" [7] (p. 17).

To confirm the perspectives outlined by Horizon 2011, today various educational experiences are carried out by augmented reality [8,9] thanks to the diffusion of simple applications to create, install and use on different mobile devices (notebook/netbook equipped with webcam, tablet, smartphone, viewers...). Thanks to such applications the vision can be enlarged and intensified by means of dynamic modes, in order to experience and know the physical environment. From a technical point 
of view augmented reality can be defined as 'a layer of information connected to an image or to a representation of the world so that the users can have the possibility to access localized information by means of extremely intuitive procedures' $[10]$ (p. 74). While virtual reality offers the simulation of an entirely computer generated perceptive experience, augmented reality devices and applications are of a see-through type since they allow the subject to see the scene by means of the digital data and such scene comes into his/her field of vision again at every movement he/she makes, in a perfect integration of real landscape and virtual 'objects'.

As a result of the development of such applications augmented reality is brought into the classroom and stimulates students' empathy through really "immersive" educational experiences. In fact, the recognition of augmented reality potential leads, both in schools and museums, to value, support and implement educational activities with methodologies based on the use of this new technology. The purpose does not consist only in the quantitative enrichment of information. 'Augmenting' reality means also providing places for cognitive growth where forms of collaborative building of knowledge and competences are carried out. Such competences can be implemented during the process and, under a theoretical perspective, are to be related to the principles of connectivism "which considers the condition of being always connected a key value for the development of knowledge in the digital era" [11] (p. 179) (See also [12-14]).

Starting from such assumptions, the present contribution wants to reflect specifically on the relationship between augmented reality and art education from the didactic mediation point of view; this study aims to reach an improved critical awareness, beyond the easy enthusiasms leading to spectacle which have accompanied the introduction of such technology in schools and museums. Infact if it is true that digital tools, with the related possibility of reproduction and manipulation of images, have transformed the way to approach the artwork and to make it known, it is also true that augmented reality technologies, involving mainly the visual dimension, represent a further evolution in the process of heritage mediation and of acquisition of proper digital skills.

Therefore, experimentations carried out at school and in museums will be taken into consideration, particularly through the documentation provided by specific studies and researches, in order to understand the ties among didactic choices, technological potential and practicability of the cognitive processes supported by augmented reality. Infact "the new technological equipment and its applications are capable of granting concrete potential if they are made available to critical models of didactic mediation and developed within a precise, careful and coherent educational project" [15] (p. 78) (See also [16]).

\section{Augmented Reality e Augmented Learning}

The use of augmented reality has a key position in the latest developments concerning the Learning with technology, which considers the new technological devices as a mean capable of promoting the learning process. Infact augmented reality can be considered as a dynamic and interactive didactic tool which contributes to transform spaces, times and modes of learning, also thanks to the fact that school laboratories and classrooms start to be widely equipped with suitable technological infrastructures. WI-FI networks, in example, allow students to be connected to the internet by managing directly their own devices in order to make researches and class activities, according to Bring Your Own Device philosophy (BYOD) [17]. As a consequence, the way the classroom is managed changes and new methodologies and didactic strategies are explored, such as simulations, gamifications, augmented reality, virtual reality and immersive learning, wearable device, mobile learning, moving the attention on the new emerging models connected to learning (immersive learning, through simulation, mixed realities learning...).

In particular the use of augmented reality has to be seen in the context of that rapidly emerging phenomenon represented by the mobile learning It is considered as a kind of learning which relies on the help of mobile devices, "leveraging on the affordances typical of such devices as: portability and flexibility, multifunctionality, ubiquity and easy accessibility, multimedia, multitouch and personal possession" [11] (p. 134) (See also [18]). Mobile learning in fact has led to develop "educational experiences based on augmented and/or mixed reality learning systems with a view to enriching the 
meaning construction activity made by the student. In this way the student will be allowed to take part in a rich media environment characterized by the combination of real and virtual objects, the use of sensory inputs and the possibility to place virtual learning objects into the real world and to virtually interact with a hybridized world" [11] (p. 134).

Furthermore, augmented reality potential appears meaningfully also within situated learning: "in a broader context of education, augmented reality is appealing because it aligns with situated learning. Students find connections between their lives and their education through the addition of a contextual layer" [7]. In fact, augmented reality, as the digital communication new frontier based on the combination of augmented contents and georeferencing, allows a just in time and just in place access to digital contents compared with real perceptive experience. Digital and real objects coexist in an 'other space' which does not substitute the physical world but overlays it "through a digital addition process, in a synchronous and interactive way, in order to provide a high content experience involving all our senses" [19] and reaching gradually increasing levels of concreteness. In fact, the complete 'transparency' of the devices (from monitor to display, from helmet to glasses) moves towards the immediacy of the experience on a perceptive, sensory and motor level. Since augmented reality offers the possibility to experiment new and creative experience-based modalities of interaction, it places itself as an active technology offering opportunity for 'immersion' and involvement on the cognitive, emotional and relational level, too.

Therefore, augmented reality fits meaningfully in the relationship between technologies and didactic mediation [10]. Its applications are within that category of mediators, the analogues, based on simulation and that Damiano [20] places among the iconic and the symbolic mediators. With reference to the model of educational architecture proposed by Clark [21] and subsequently integrated [22], the learning centred on the use of augmented reality plays a relevant role in the simulative architecture and recognizes the very symbolic simulation as its main didactic strategy. Such strategy "is based on reproducing, in a protected and controllable context, experiences similar to the ones in the real world, in order to provide students with the possibility of acting and learning from the consequences of their own actions (...) through a kind of involvement both intellectual and emotional" [11] (p. 68), leading to "reconceptualize the didactics in a more interactive and partecipated way" [11] (p. 133).

Taking into consideration the school context, the application of augmented reality occurs according two different modalities:

1. as a support to the user-students who, within an 'augmented' environment, detect and frame the graphic elements which, as a result, give access to the formative contents required to describe and tell about a specific experience-based context; also augmented books fit into this field "aiming to strengthen printed media through the collocation of paper markers on covers and pages (...): photos turn into videos, paragraphs become animated and columns give way to graphic and multimedia objects" [9] (p. 43).

2. as a product by the programmer-students who, after learning the basic principles of design through augmented reality, create augmented contents by their smartphone/tablet, starting from the research and selection of interesting and relevant study materials. In this way "students can build the contents and place them in the context through their smartphone or tablet; such contents become accessible by other students who can then add further contents" [11] (p. 135).

Concerning this second mode of operation, various pilot schools in Italy have started laboratorial projects which require the carrying out of augmented didactic activities, based essentially on four fundamental actions: searching and selecting information; building augmented images (texts, videos...); augment the original images; share the augmented contents.

There are two main applications which are used for the creation of augmented experiences, Quiver and Aurasma, both free and used in different school contexts.

Quiver is an application mainly used in primary schools which provides downloadable, printable and colouring pages; then it proceeds to the scanning through the mobile device camera, in order to animate objects, animals and other coloured images. Through Aurasma instead every image, object or place can have its very "aura", that is can offer an augmented experience, starting from an initial picture which, if framed, works as a trigger image of the overlay. Overlay elements can be of four 
types (images, videos, websites and 3D objects) and offer various opportunities as far as didactics is concerned, with the possibility of integrating learning with multiple additional multimedia contents. As a result, augmented learning occurs [23,24]; also, through classroom reproduction of real life scenarios which go beyond the pure theoretical dimension, in order to produce "different thinking styles, preparing for creative and divergent solutions to contemporary life problems" [25].

To such regard different national and international studies [26-28] have pointed out relevant aspects related to augmented reality application in educational contexts, with particular reference to the capacity to develop autonomy in the cognitive process; to promote self-learning conditions which guarantee the respect of different times/rhythms; to favour the implementation of a discovery, exploration and research operational methodology; to strengthen collaborative learning among students; to point out the reticular, hypertext and complex structure of knowledge, facilitating the integration within different subject areas; lastly, to understand, describe, interpret and rethink the real, by developing a 'creative mind' and new 'Know Hows'.

\section{Augmented Reality for Art Education}

Some recent studies, both in a national and international context, focus on the relationship between augmented reality and art education and on its potential [29,30]. In particular the use of augmented reality in educational contexts relating to artistic heritage refers to the acquisition of two of the key competences recommended by the European Council for lifelong learning: the 'digital competence' and the 'cultural awareness and expression'. Specifically, the 'digital competence' consists of "the competent and critical use of the Information Society Technologies (TSI) for work, free time and communication (...), find, value, preserve, produce, present and exchange information and also communicate and participate in collaborative networks through Internet". Instead the main feature of the second key competence is to be found in the 'awareness of the importance of the creative expression of ideas, experiences and emotions in a range of media, including music, performing arts, literature and the visual arts" and includes "an awareness of local national and European cultural heritage and its place in the world (...) and a basic knowledge of major cultural works, including popular contemporary culture". Such competence refers to skills related to "the appreciation and enjoyment of works of art and performances as well as self-expression through a variety of media" (Recommendation by European Parliament and Council, 18th December 2006, relating to key competences for lifelong learning). This last feature is well emphasized also in the Road Map for art education; this document is the outcome of the first UNESCO world conference on creative skills development for XXI century (Lisbon, 6-9 March 2006) and recognises the need to incorporate the new technologies "formal, non formal and informal educational processes, as a mean of creation, artistic expression, reflection and critical thinking" (UNESCO, Road Map for art education).

Furthermore, the design and experimentation of augmented reality paths within the cultural heritage and specifically the artistic one, satisfies some of the educational objectives specified in Legge 107/2015 (Riforma del sistema nazionale di istruzione e formazione e delega per il riordino delle disposizioni legislative vigenti, art.1, comma 7):

- $\quad$ enhancing the competences (...) related to art and art history, techniques and media for images and sound diffusion, also through the involvement of museums and other public and private institutions operating in such fields;

- development of the competences related to democratic and active citizenship through the appreciation of intercultural education;

- art, techniques and media literacy, with specific reference to media for images and sound diffusion;

- development of students' digital skills;

- appreciation of school considered as an active community, open to territory and capable of fostering and expanding the interaction with families and local community.

Recently, in order to raise awareness among young people about the active role of new technologies in the appreciation of the cultural heritage, MIUR (Italian Ministry for Education, University and Research) has published a Notice addressed to all educational institutions for the 
development of landscape, art and cultural education. Such notice refers to the PON 2014-2020 framework programme actions conceived specifically as "access, exploration, knowledge and appreciation, also digital through technological experimenting, of the heritage.

In fact, museums and, more generally speaking, the arts and cultural heritage are considered as places of knowledge transmission "where people's memory is collected, places which preserve the objects and the information of the civilisation which generated them: as Manovich would put it (...) they are big dataspace" [9] (p. 138). Each object preserved in a museum is not only a simple datum, yet includes and hides its own story which technologies, and in particular augmented reality devices, are capable to tell. By exploiting the very digital connective capacity, new applications connect "each datum to many others related to the social environments which, overtime, generated or made use of it. This social framework allows to represent a cultural object without isolating it from the context it belongs to; in this way its nature of datum enriches and turns into narration.

In this respect the use of augmented reality within art education can be declined according two different modalities, with reference to the dual role of the subject (student, visitor...) of user vs. programmer both in formal educational contexts and in non-formal ones: augmented reality for museum fruition and augmented reality for creative expression.

\subsection{Augmented Reality for Museum Fruition}

The relationship between augmented reality and learning is particularly meaningful in the museum context. The use of various mobile devices turns the space assigned to the exhibition of art works, and generally speaking, the places of culture, into digitally augmented environments. Augmented reality, infact, as a new didactic mediator (supporting the information panels inside the rooms) proposes augmented exhibit pathways which show the work in its original context, provide information which are not ready to be used or, what's more, allow to see an exhibit reconstructed in real time [31]. To be more precise augmented reality technologies can be applied to cultural heritage in dual mode: indoor and outdoor [32,33]. In the case of augmented reality indoor the visitor, through his/her own mobile device or through the one provided by the very institution, scans the trigger image and in this way can question actively the works and explore them without having to effectively touch them, giving rise to an enriched visit expanding the range of possibilities connected to the fruition experience. The augmented subjects, stories, details overlap in this way with the original work, facilitating its understanding.

Augmented reality also offers the possibility of seeing monuments as they were in the past. A meaningful example is Ara Pacis in Rome, which, through special visors AR (Samsung Gear VR), allows to experience an immersive and multisensorial visit where virtual and real elements merge directly in the visitors' field of view, with the recovery of the original colours of the ancient monument [34] (Figure 1). 


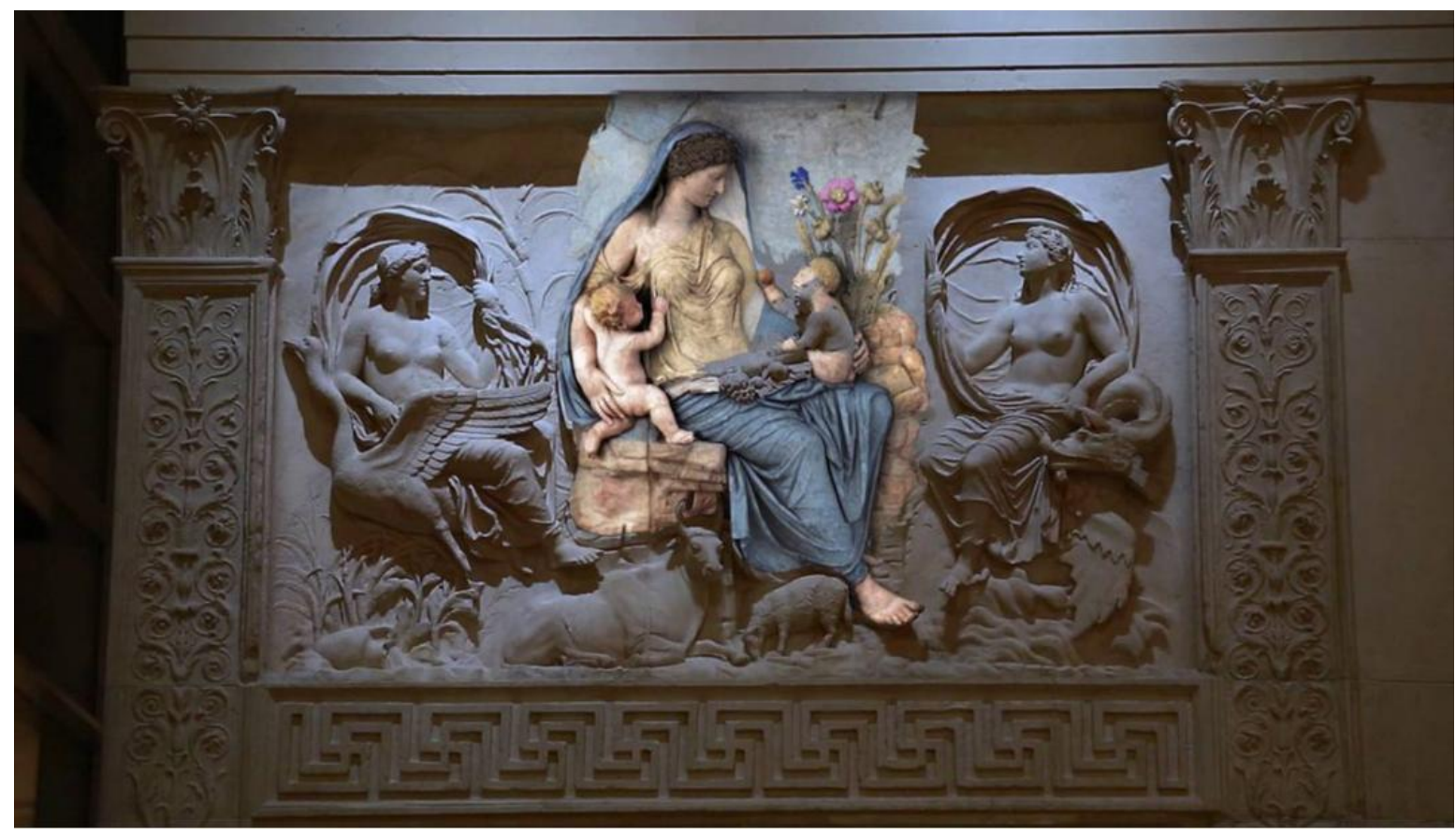

Figure 1. L'Ara com'era. Un racconto in realtà aumentata del Museo dell'Ara Pacis, Roma. Retrieved from: http://www.arapacis.it/mostre_ed_eventi/eventi/l_ara_com_era.

At the Royal Palace of Monza visitors can wear ArtGlass glasses and consequently move freely around the apartments on the noble floor and have access to information, which would not be available only through direct observation, about the rooms, furnishings and historical facts which characterized them [35].

Augmented reality applies also and in particular to outdoor mobile cultural fruition which provides visitors with the possibility to move around the physical spaces of a city (or of an archeological area), viewing detailed contents and 3D images overlapped with contemporary buildings and places (Figure 2). Also, in this case the real vision is enriched with the picture of the place as it was like in the past (the way it was like compared to the way it is like) or what it will be like in the future in case of architectural and urban design (the way it will be like compared to the way it is like). 


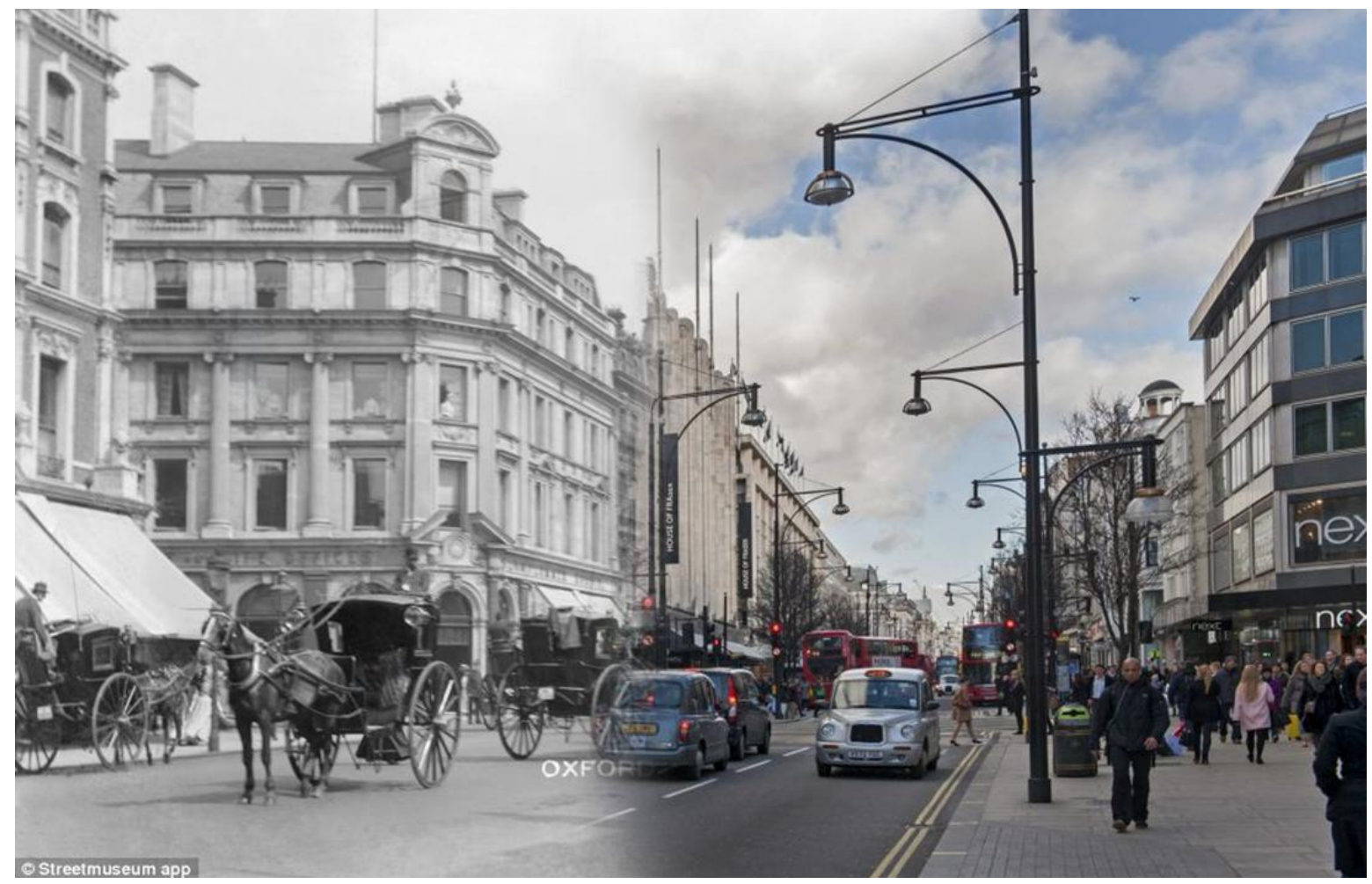

Figure 2. Streetmuseum, augmented reality app created by The Museum of London.

In both modes indoor and outdoor, augmented reality applications are based on a high reproduction digital restitution, where virtual reconstruction elements overlap with the real ones, in an immersive experience which returns the impression of being in front of a unique object, monument or landscape.

Augmented fruition renews and updates the mediation modalities of the heritage and the associated forms of learning. The visitor moving around in a given space, changes his/her view angle and every time chooses what to see or deepen. In this way he/she enters "a new narrative space, consisting in the analogical datum and its story", where the physical data are augmented by means of the digital narrations [9] (p. 139). Such technological transformation demands "a new cultural approach since it requires to rethink the construction of self identity, the vision of urban spaces and the modes of appreciation of artistic and cultural products" [36], especially by the new generations, fascinated by the possibility of interacting with the work of art and its context of reference, but also to carry out creative revisions and interpretations.

In this respect some young artists working in the digital field use augmented reality within museum fruition in a really original way and in a recreational/collaborative dimension that moves users to deal with the works through a creative reinterpretation developed in a modern way. A meaningful example is ReBlink-project hosted by Art Gallery of Ontario (Toronto) in 2017developed by the artist Alex Mayhew; thanks to such project the works of art displayed in the museum can be animated thanks to a personalized application for smartphones and tablets. The characters portrayed in some paintings, animated and brought to the contemporary world, begin to interact with the visitor (leave the frame, take selfies...). In this way reality and imagination become interwined and as a result past art is put in relation with new generations and opens the way to creative experimentations (Figure 3). 

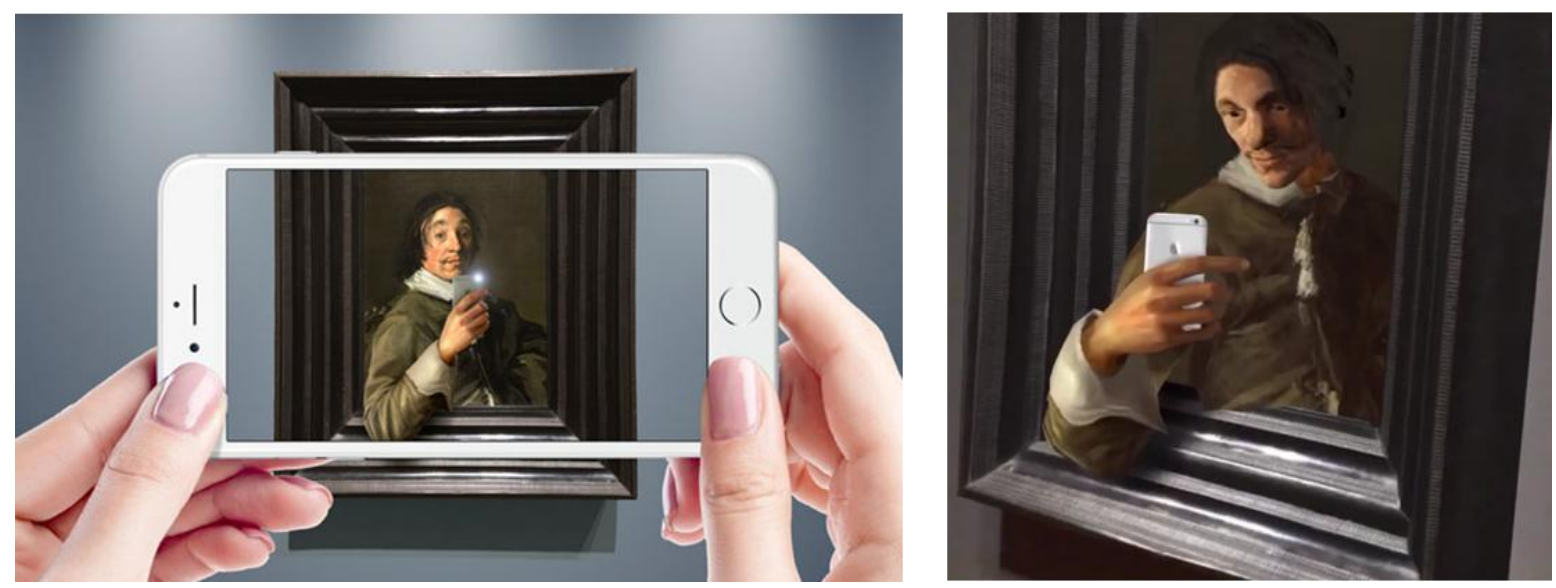

Figure 3. Alex Mayhew, ReBlink, 2017, Art Gallery of Ontario. Retrieved from: http://www.ago.net/reblink.

\subsection{Augmented Reality for Creative Expression}

Augmented reality, as a tool that young people use to express themselves and re-elaborate the acquired knowledge especially in art and cultural heritage education, is more and more reflected in primary and particularly secondary school contexts. The findings of a recent study are relevant in order to be able to outline a preliminary picture of the impact of augmented didactic activities related to artistic educational pathways. It concerns a qualitative study, Augmented reality in art education, carried out by Devin Smith of the Department of Educational Technology of Arizona University, aimed at examining the possible ways through which augmented reality influences art education, through questionnaires on the students' views. The case study proposed by Smith involves sixty students coming from different school levels (from 3rd to 10th) engaged in didactic activities concerning art education and art history (The youngest students used Quiver, the oldest ones Aurasma) and carried out through augmented reality. Once the activities were over, the students answered nine-ten questions collecting their opinions on the use of augmented reality in art lessons. What comes to light with evidence is that the youngest students (3rd-6th) have already experimented augmented reality through videogames (Pokemon GO) and consider the application of such technology to art funny. Most of the answers show furthermore that the students learnt art better through augmented reality ( $A R$ helped me to learn art) so much that they wanted to go on using it. The answers from students at the 9th and 10th grade are very meaningful: besides finding augmented reality very interesting, with reference to the question: Do you feel that augmented reality changes the way people view your artwork?, they wrote that: 1. people get to see the process; 2 . final art work becomes more meaningful; 3. artwork is more participatory; 4. process is as important product.

To summarize almost all the students gave a positive feedback about the use of augmented reality in art lessons. "Ultimately, the possibilities for AR in art education are many and the technology's ability to add breadth and depth to learning is there, as long as it's utilized in an appropriate and meaningful way. As AR and other digital media continue to develop and change, so too should art education" [30]. Infact augmented reality technologies offer children and young people the tools to explore, know and talk to the territory and the city heritage, through the search for information, the construction and the sharing of personal contents capable of providing new readings and open new perspectives.

In Italy there are various pilot schools which, in recent years, are experimenting augmented didactics pathways where young people use augmented reality as a form of creative expression. The students design didactic art projects with their teachers to be carried out in class within augmented learning and learn how to observe, interact and finding out about the artistic heritage in an active and interactive way. In such regard two augmented reality projects are relevant, respectively indoor and outdoor: the project of an exhibition on "The plague of 300" and the STar project. 
The first project proposing the use of indoor augmented reality for the creation of an exhibition on The plague of 300 [37]; involved a fourth class of the liceo scientifico of "La Rosa Bianca" in Cavalese (Trento). In order to implement the project, the students searched for the sources on the internet and at the library, re-elaborated the materials and prepared the augmented panels focusing the attention on the different aspects connected to the plague and its representation in art.

The project STar (Segesta Tigulliorum-augmented reality), proposed by the Istituto Comprensivo in Sestri Levante in collaboration with MuSel (Museo Archeologico in Sestri Levante), has been funded by MIUR within the national competition notice "Didactic projects in museums, archeological, historical and cultural sites or in cultural and scientific institutions. This project aims first of all to implement an augmented guided tour which makes the historical city centre accessible and then to involve young people about the conscious fruition issue as well as the sense of belonging to heritage. The project STar 2016 involved two classes of Istituto Comprensivo in Sestri Levante in collaboration with The Archeological Museum. Specifically, the students studied the two guided tours with stopovers to propose within the city (via dei Palazzi and via delle Chiese) and created the profiles of two "talking avatars" guiding the visitor through an augmented reality app (Figure 4) App developed by computer technicians of Liguria Digitale, downloadable from Liguria Heritage website and through QR code inserted in the signs specially prepared and accessible to tourists along the routes.

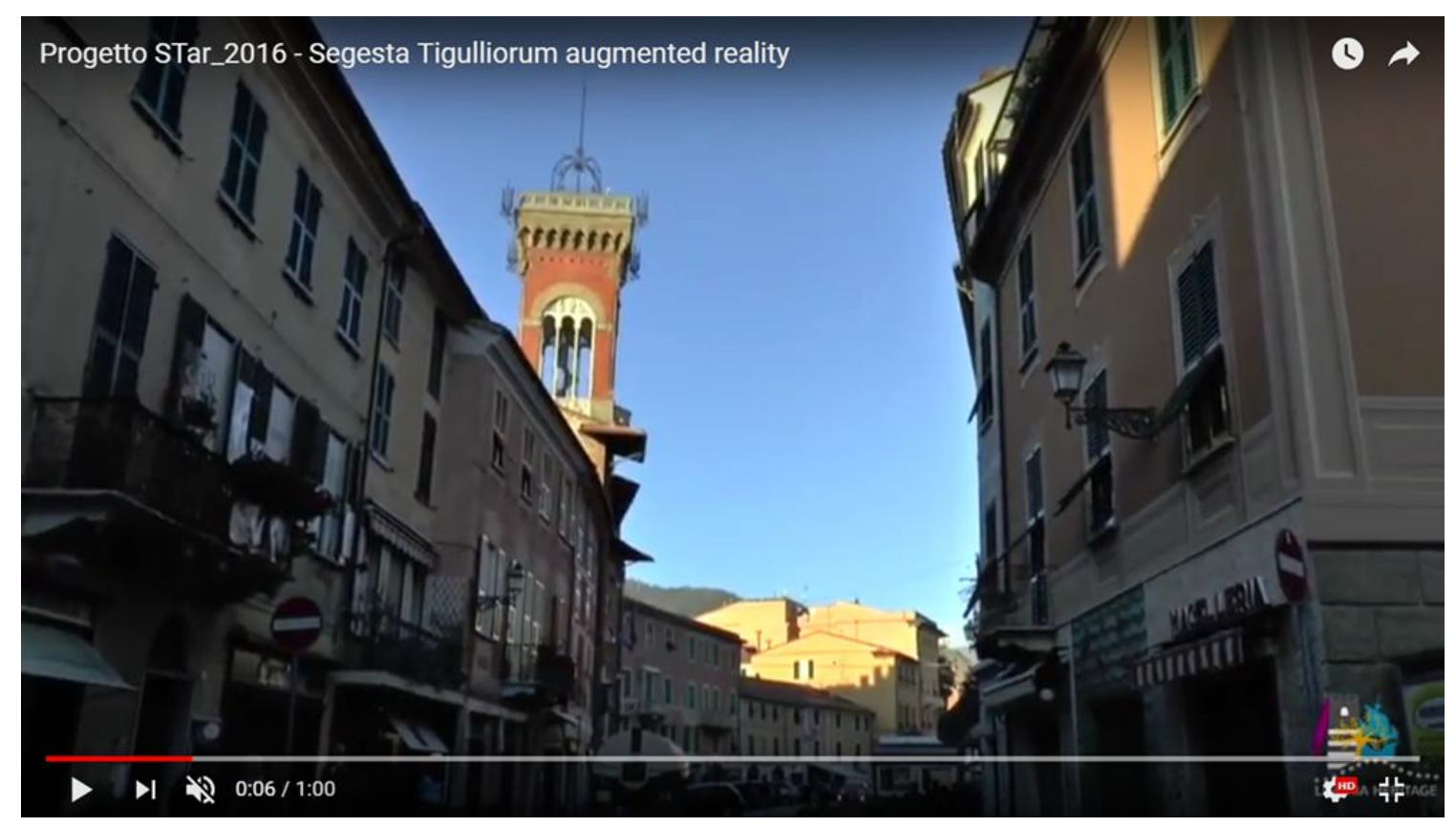

Figure 4. Progetto STar_2016-Segesta Tigulliorum augmented reality. Retrieved from: https://www.youtube.com/watch?v=tg11aWcwtVU.

\section{Conclusions}

Considering the increasing use of technologies in art education and heritage appreciation, augmented reality works as a stimulating agent, aiming to discover new cultural objects and original approaches, within real emotional pathways stirring up interest and passion especially in the youngest ones. In such regard Daniel Lanfrey stresses the necessity to ask "schools and students" in partnership with public and private organisations, local authorities and cultural innovators, to suggest innovative reading keys to promote the territory heritage and then to implement them". In order to have all this carried out it is necessary to "work with the perspective of urban regeneration (...), by digitising part of the heritage or producing digital solutions, or simply by enriching it with suitable cultural productions" [38].

Therefore, augmented reality technologies introduce new modalities of enjoying heritage and art, with a relevant impact on imagination, emotional experience and cognitive growth. The people 
who use new augmented reality technologies experiment a different kind of convergence among knowledge, creativity and imagination, according to immersive modalities where real and virtual mix in inextricable way. Furthermore, "AR has the potential to increase collaboration and opportunities for students to share what they're learning in new ways" [30] (p. 11). The possibilities of to add breadth and depth to art education are many, as long as augmented reality is utilized in a meaningful way in a perspective of cognitive and creative development.

Translated by Simona Candeli, Unibo, Primary Education Sciences.

Conflicts of Interest: The authors declare no conflicts of interest.

\section{References}

1. Billinghurst, M.; Duenser, A. Augmented reality in the classroom. Computer 2012, 45, 56-63.

2. Brown, P. How to Transform Your Classroom with Augmented Reality. EdSurge News 2015. Available online:https://www.edsurge.com/news/2015-11-02-how-to-transform-your-classroom-with-augmentedreality (accessed on 5 March 2017).

3. Duty, R. Technology in Education-the Effect of VR and AR. VR/Focus 2017. Available online: https:// www.vrfocus.com/2017/08/technology-in-education-the-effect-of-vr-and-ar/ (accessed on 4 October 2017).

4. Rivoltella, P.C. Oltre il virtuale: La nostra è una "realtà aumentata". Vita Pensiero 2010, 5, 102-108.

5. Chen, P.; Liu, X.; Cheng, W.; Huang, R. A Review of Using Augmented Reality in Education from 2011 to 2016. In Innovations in Smart Learning; Springer: Singapore, 2017.

6. Salmi, H.; Thuneberg, H.; Vainikainen, M.P. Making the Invisible Observable by Augmented Reality in Informal Science Education Context. Int. J. Sci. Educ. 2016. Available online: http://www.tandfonline.com/doi/ pdf/10.1080/21548455.2016.1254358?needAccess=true\& (accessed on 5 October 2017).

7. Johnson, L.; Smith, R.; Willis, H.; Levine, A.; Haywood, K. The 2011 Horizon Report; The New Media Consortium: Austin, TX, USA, 2011. Available online: http://www.nmc.org/sites/default/files/pubs/131 6814265/2011-Horizon-Report(2).pdf (accessed on 12 May 2017).

8. Azuma, R.T. A Survey of Augmented Reality. Presence Teleoper. Virtual Environ. 1997, 6, 355-385.

9. Simonetta, G. Realtà Aumentate. Esperienze, Strategie e Contenuti per L'Augmented Reality; Apogeo: Milano, Italy, 2012.

10. Rossi, P.G. Realtà Aumentata e Mediazione Didattica. In Pedagogia Nell'Era Digitale; Persico, D., Midoro, V., Eds.; Edizioni Menabò: Ortona, Italy, 2013; pp. 73-76.

11. Bonaiuti, G.; Calvani, A.; Ranieri, M. Fondamenti di Didattica. Teoria e Prassi dei Dispositivi Formativi; Carocci: Roma, Italy, 2016.

12. Calvani, A. Connettivismo: Nuovo paradigma o ammaliante pot-pourri?. J. E-Learn. Knowl. Soc. 2008, 4, 121-125.

13. Siemens, G. Connectivism: A Learning Theory for the Digital Age. Int. J. Instr. Technol. Distance Learn. 2005, 2. Available online: http://www.itdl.org/Journal/Jan_05/article01.htm (accessed on 12 September 2017).

14. Techakosit, S.; Wannapiroon, P. Connectivism Learning Environment in Augmented Reality Science Laboratory to Enhance Scientific Literacy. Procedia Soc. Behav. Sci. 2015, 174, 2108-2115.

15. Panciroli, C. Le Arti Visive Nella Didattica. Teorie, Esperienze e Progetti Dalla Scuola Dell'infanzia Alla Scuola Secondaria; QuiEdit: Verona-Bolzano, Italy, 2012.

16. Panciroli, C. Le Professionalità Educative Tra Scuola E Musei. Esperienze e Metodi Nell'Arte; Guerini: Milano, Italy, 2016.

17. Grant, M.M.; Tamim, S.; Sweeney, J.P.; Ferguson, F.K. Teaching and learning with mobile computing devices: Case study in K-12 classrooms. TechTrends 2015, 59, 32-45.

18. Ranieri, M.; Pieri, M. Mobile Learning. Dimensioni Teoriche, Modelli Didattici, Scenari Applicativi; Unicopli: Milano, Italy, 2014.

19. Bisogni, M. Realtà Aumentata. Per la Comunicazione di Prodotto; Tecniche Nuove: Milano, Italy, 2014.

20. Damiano E. La Mediazione Didattica. Per Una Teoria Dell'insegnamento; Franco Angeli: Milano, Italy, 2013.

21. Clark, R.C. Four Architectures of Instruction. Perform. Improv. 2000, 39, 31-38.

22. Calvani, A. Principi Dell'istruzione e Strategie Per Insegnare. Criteri per Una Didattica Efficace; Carocci: Roma, Italy, 2011. 
23. Gabbari, M.; Gagliardi, R.; Gaetano, A.; Sacchi, D. Comunicazione e Apprendimento "Aumentati" in Classe-Fare Lezione a Scuola Con la Realtà Aumentata. Bricks 2017, 1, 8-30. Available online: http://bricks.maieutiche.economia.unitn.it/2017/03/12/comunicazione-e-apprendimento-aumentati-inclasse-fare-lezione-a-scuola-con-la-realta-aumentata/ (accessed on 3 September 2017).

24. Herrington, K.S.; Crompton, H. Augmented Learning with Augmented Reality. In Mobile Learning Design; Springer: Singapore, 2015.

25. Arduini, G. La realtà aumentata e nuove prospettive educative. Educ. Sci. Soc. 2012, 3, 209-216

26. Diegmann, P.; Schmidt-Kraepelin, M.; Van Den Eynden, S.; Basten, D. Benefits of Augmented Reality in Educational Environments-A Systematic Literature Review, 2015, pp. 1542-1556. Available online: http://www.wi2015.uni-osnabrueck.de/Files/WI2015-D-14-00036.pdf (accessed on 28 May 2017).

27. Echeverría, A.; Gil, F.; Nussbaum, M. Classroom Augmented Reality Games: A Model for the Creation of Immersive Collaborative Games in the Classroom, 2016. Available online: https://pdfs.semanticscholar.org/ 1413/85717d0c961f79a136a9c8b3388b516104a6.pdf (accessed on 15 October 2017).

28. Pemberton, L.; Winter, M. Collaborative Augmented Reality in Schools; University of Brighton: Brighton, UK, 2009. Available online: http://ltee.org/uploads/cscl2009/paper236.pdf (accessed on 6 September 2017).

29. Di Serio, Á.; Ibáñez, B.M.; Kloos, C.D. Impact of an augmented reality system on students' motivation for a visual art course. Comput. Educ. 2013, 68, 586-596.

30. Smith, D. Augmented Reality in Art Education; The University of Arizona Libraries, 2016. Available online: http://arizona.openrepository.com/arizona/handle/10150/621860 (accessed on 16 February 2017).

31. Spallazzo, D. Musei, Fruizione Culturale e Tecnologie Mobili. Luoghi, Persone, Storie. Storicamente 2013, 9 , doi:10.1473/stor463. Available online: http://storicamente.org/sites/default/images/articles/media/ 1763/spallazzo.pdf (accessed on 24 March 2016).

32. Bonacini, E. Nuove Tecnologie per la Fruizione e la Valorizzazione del Patrimonio Culturale; Aracne Editrice: Roma, Italy, 2011.

33. Bonacini, E. La realtà aumentata e le app culturali in Italia: Storie da un matrimonio in mobilità. Capitale Cult. Stud. Value Cult. Heritage 2014, 9, doi:10.13138/2039-2362/740.

34. Ara as it was like. An augmented reality narration of the Ara Pacis Museum. Available online: http://www.arapacis.it/mostre_ed_eventi/eventi/1_ara_com_era (accessed on 13 September 2017)

35. Never been so Real! Augmented guided tours. Available online: http://www.reggiadimonza.it/ it/content/things-to-do/mai-stata-cos\%C3\%AC-reale-visite-guidate-aumentate (accessed on 27 October 2017)

36. Lughi, G. Spazi Urbani, Come il Digitale ne Cambia la Cultura, 2017. Available online: https://www.agendadigitale.eu/senza-categoria/citta-arte-tecnologie-come-cambia-la-cultura-degli-spaziurbani-col-digitale/ (accessed on 4 September 2017).

37. Alotto, P.; Corradini, B. La Peste del '300. Una mostra in realtà aumentata. Bricks 2017, 1, 58-65

38. Lanfrey, D. Competenze Degli Studenti, Miur: "Si Compie la Prima Chiamata al Sistema Scuola", Agenda Digitale, 2017. Available online: https://www.agendadigitale.eu/scuola-digitale/competenze-degli -studenti-miur-si-compie-la-prima-chiamata-al-sistema-scuola/ (accessed on 12 September 2017).

(C) 2018 by the authors. Licensee MDPI, Basel, Switzerland. This article is an open access article distributed under the terms and conditions of the Creative Commons Attribution (CC BY) license (http://creativecommons.org/licenses/by/4.0/). 